\title{
An Outlook on Cost Analysis among Common Oral Antihypertensive Medications of various Brands Available in Indian Pharmaceutical Companies
}

\author{
Authors \\ B. Jagan Nathan ${ }^{1}$, S. Sabishruthi ${ }^{* 1}$, S. Kavitha ${ }^{1}$, S. Sindhu ${ }^{1}$, S.Punitha ${ }^{1}$ \\ ${ }^{1}$ Department of Pharmacy Practice, Jaya College of Paramedical Sciences, College of Pharmacy, \\ Thiruninravur, Chennai - 602024 \\ *Corresponding Author \\ S. Sabishruthi \\ Department of Pharmacy Practice, Jaya College of Paramedical Sciences, College of Pharmacy, \\ Thiruninravur, Chennai - 602024, India
}

\begin{abstract}
Aim: The current study was performed to analyse the percentage of cost variations of commonly prescribing antihypertensive medications among different brands of same drugs in India.

Materials and Methods: The data of cost of commonly used antihypertensive drugs were collected from CIMS and IDR, which may provide accurate drug information. Additionally the drug prices are also checked in retail pharmacy. Data about the cost of oral antihypertensive drugs were collected as cost per 10 tablets in same strength and same dosage forms that was manufactured from different companies and they were compared to find the variation of cost. Combinations of drugs were excluded from the study. Cost ratio and percentage of cost were calculated using applicable formulae.

Results: Out of 23 drugs of different doses without combination Tablet Amlodipine (5 mg) shows the maximum price variation of 460\%, followed by Tablet Enalapril (10 mg) 374.28\%, Tablet Olmesartan (20 mg) 404.41\%, Tablet Amlodipine (5 mg) $460 \%$ and Tablet Atenolol $100 \mathrm{mg} 424.66 \%$ variation.

Conclusion: The study reveals that there was a huge variation of cost in drugs which was manufactured from various pharmaceutical companies. Hence physicians can prescribe the drugs in generic forms. An awareness must be created about the maximum variation of cost to the physicians, pharmacist and health care management to our economic benefits for patients and increase their benefits of therapy.

Keywords: Cost, Antihypertensive drugs, Brands, Physician, Benefits.
\end{abstract}

\section{Introduction}

In developing countries like India, hypertension is the one of the major primary etitology of many cardiovascular diseases and other events either in a direct mode or indirect mode. Furthermore, it is the leading risk factor for morbidity and mortality $^{(1)}$. Its prevalence has major impact in worldwide; In India it varies about $17-21 \%$ and it requires lifelong treatment. Moreover, it has been the major cause for $10 \%$ of all death in the world $^{(2)}$. According to epidemiology; approximately 1 billion people had hypertension 
globally in 2010 and Studies showed that about 1.56 billion people will have hypertension by $2025^{(3)}$.

These cardiovascular complications such as hypertension can be prevented with pharmacological and non-pharmacological medications. There are certain common antihypertensive drugs are been prescribing major for past few years and they are Angiotension Converting Enzymes (ACE) inhibitors, Angiotensin antagonist, Calcium channel blockers (CCB), $\beta$ - Adrenergic blockers, $\alpha-$ adrenergic blockers, vasodilators and centrally acting sympatholytic agents ${ }^{(4)}$. Hypertension requires long term treatment which may mount the expenses of health care and may create some burden to low socio economic patients which also leads to some psychological conditions such as stress, etc. Hence it reduces the patient'stherapeutic compliance ${ }^{(5)}$. In developing countries like India, pricing of drugs is a sensitive issue and economics has major role in determining compliance with the treatment of disease like hypertension ${ }^{(6)}$. Although, there are lots of pharmaceutical industries in India, there is huge difference in drug price of antihypertensive drugs of same formulation. For a single generic drug in India, there are multi brands are available with huge variety of prices and became a competitive world of both domestic and foreign manufactures in pharmafield ${ }^{(7)}$.

Here, we planned to focus our study on 'Cost analysis' of different brands of same drug. Cost analysis is a type of pharmacoeconomic which compares the costs of two or more alternatives without regard to outcome.Analysis of cost variation can provide a knowledge about the interbrand price variation and helps to give financial support partiallyfor patients. There are few studies shown a wide variation on cost of Indian market ${ }^{(8,9)}$.

Hence the present study was aimed to compare the cost difference of multi branded drugs used in Indian market, by collecting data about cost of drugs commonly prescribed for hypertension.

\section{Materials \& Methods}

The maximum and minimum costs of different brands of antihypertensive drugs were collected from CIMS- Jan 2019 (current index of medical specialties) and IDR - Jan 2019 (Indian drug review) which may provide accurate drug information. Additionally the drug prices are also checked in retail pharmacy. Data about the cost of oral antihypertensive drugs were collected as cost per 10 tablets in same strength and same dosage forms that was manufactured from different companies and they were compared to find the variation of cost.Combinations of drugs were excluded from the study.

Analysis of data was performed by identifying the maximum and minimum price for different oral antihypertensive drugs and they were calculated. These are the following formulas were used to calculate the cost variation of drugs.

Cost ratio between the maximum and minimum cost of the same drug manufactured by different pharmaceutical companies was calculated as follows:

- Cost ratio= Maximum cost $/$ Minimum cost

- $\%$ cost variation was calculated as follows:

- $\%$ cost variation

$=\underline{(\text { Maximum cost }- \text { Minimum cost }) \times 100}$

Minimum cost

\section{Result}

The cost of commonly used oral antihypertensive drugs (23 drugs of different doses without combination) manufactured by different pharmaceutical companies were analysed. Of overall (Table 1) Tablet Amlodipine (5 mg) shows the maximum price variation of $460 \%$, while Tablet methyldopa $(250 \mathrm{mg}$ ) shows the minimum price variation of $10.93 \%$. Table 1 shows the maximum and minimum percentage of price variation for common antihypertensive drugs. ACE Inhibitors: Tablet Enalapril $(10 \mathrm{mg})$ $374.28 \%$ and Tablet Ramipril (10 mg) $73.04 \%$, Angiotensin antagonist:Tablet Olmesartan (20 mg) $404.41 \%$ and Tablet Candesartan (4 mg) 25.67\%, Calcium channel blockers:Tablet Amlodipine (5 mg) 460\% and Tablet Nifedipine 
(5 mg) 11.38\%, $\beta$-blockers: Tablet Atenolol 100 $\mathrm{mg} 424.66 \%$ and Tablet Labetolol $100 \mathrm{mg}$ $12.29 \%$, Centrally acting sympatholytic drugs shows the minimum cost variation of Tablet
Methyldopa (250 mg) 10.93\%, $\alpha$-blockers: Tablet Prozion (2.5 mg) $42.75 \%$ and Prozion $(5 \mathrm{mg}$ ) $16.41 \%$, Vasodilators:Tablet Cinnarizine $(25 \mathrm{mg}$ ) $165.45 \%$ and Tablet Isoxsuprine (40 mg) $25 \%$.

Table 1: Cost variation analysis of common antihypertensive drugs

\begin{tabular}{|c|c|c|c|c|c|c|}
\hline \multicolumn{7}{|c|}{ ACE Inhibitors } \\
\hline S.No & Drug Name & Dose & $\begin{array}{c}\text { Maximum } \\
\text { Cost } \\
\text { (Inr) }\end{array}$ & $\begin{array}{l}\text { Minimum } \\
\text { Cost } \\
\text { (Inr) }\end{array}$ & $\begin{array}{c}\text { Cost } \\
\text { Variation } \\
(\%)\end{array}$ & $\begin{array}{l}\text { Cost } \\
\text { Ratio }\end{array}$ \\
\hline \multirow[t]{3}{*}{1.} & \multirow{3}{*}{ T. Enalopril } & $2.5 \mathrm{mg}$ & 29.24 & 6.75 & 333.18 & 4.33 \\
\hline & & $5 \mathrm{mg}$ & 50.57 & 14.22 & 255.62 & 3.55 \\
\hline & & $10 \mathrm{mg}$ & 99.60 & 21 & 374.28 & 4.74 \\
\hline \multirow[t]{3}{*}{2.} & \multirow{3}{*}{ T. Lisnopril } & $2.5 \mathrm{mg}$ & 50 & 13.50 & 270.37 & 3.70 \\
\hline & & $5 \mathrm{mg}$ & 100 & 25 & 300 & 4 \\
\hline & & $10 \mathrm{mg}$ & 108.25 & 50.78 & 113.17 & 2.13 \\
\hline \multirow[t]{4}{*}{3} & \multirow[t]{4}{*}{ T. Ramipril } & $1.25 \mathrm{mg}$ & 32.11 & 12.50 & 156.88 & 2.56 \\
\hline & & $2.5 \mathrm{mg}$ & 56.84 & 25 & 127.36 & 2.27 \\
\hline & & $5 \mathrm{mg}$ & 97.02 & 45 & 115.6 & 2.156 \\
\hline & & $10 \mathrm{mg}$ & 130.04 & 75.15 & 73.04 & 1.73 \\
\hline \multirow[t]{3}{*}{4.} & \multirow[t]{3}{*}{ T. Perindopril } & $2 \mathrm{mg}$ & 111 & - & N/A & N/A \\
\hline & & $5 \mathrm{mg}$ & 130 & - & N/A & N/A \\
\hline & & $10 \mathrm{mg}$ & 160 & - & N/A & N/A \\
\hline \multicolumn{7}{|c|}{ Angiotensin antagonist } \\
\hline \multirow[t]{2}{*}{5.} & T. Losartan & $25 \mathrm{mg}$ & 43.47 & 15.50 & 180.45 & 2.80 \\
\hline & & $50 \mathrm{mg}$ & 85.86 & 29.50 & 191.05 & 2.91 \\
\hline \multirow[t]{2}{*}{6.} & T. Candesartan & $4 \mathrm{mg}$ & 34.95 & 27.81 & 25.67 & 1.25 \\
\hline & & $8 \mathrm{mg}$ & 61.80 & 45.27 & 36.51 & 1.36 \\
\hline \multirow[t]{2}{*}{7.} & T. Olmesartan & $20 \mathrm{mg}$ & 171.50 & 34 & 404.41 & 5.04 \\
\hline & & $40 \mathrm{mg}$ & 163 & 54 & 201.85 & 3.02 \\
\hline \multirow[t]{3}{*}{8.} & T. Telmisartan & $20 \mathrm{mg}$ & 42 & 27.82 & 50.97 & 1.50 \\
\hline & & $40 \mathrm{mg}$ & 80 & 27 & 196.27 & 2.96 \\
\hline & & $80 \mathrm{mg}$ & 114 & 74.95 & 92.12 & 1.52 \\
\hline \multicolumn{7}{|c|}{ Calcium channel blockers } \\
\hline \multirow[t]{3}{*}{9.} & T. Nifedipine & $5 \mathrm{mg}$ & 12.03 & 10.80 & 11.38 & 1.11 \\
\hline & & $10 \mathrm{mg}$ & 19.40 & 13.23 & 46.63 & 1.46 \\
\hline & & $20 \mathrm{mg}$ & 29.10 & 18 & 61.66 & 1.61 \\
\hline \multirow[t]{3}{*}{10.} & T. Felodipine & $2.5 \mathrm{mg}$ & 22 & - & N/A & N/A \\
\hline & & $5 \mathrm{mg}$ & 39 & - & N/A & N/A \\
\hline & & $10 \mathrm{mg}$ & 69 & - & N/A & N/A \\
\hline \multirow[t]{3}{*}{11.} & T. Amlodipine & $2.5 \mathrm{mg}$ & 27.75 & 8.80 & 215.34 & 3.15 \\
\hline & & $5 \mathrm{mg}$ & 70 & 12.50 & 460 & 5.6 \\
\hline & & $10 \mathrm{mg}$ & 53.30 & 30 & 77.66 & 1.77 \\
\hline 12. & T. Cilnidipine & $5 \mathrm{mg}$ & 49.50 & 25 & 98 & 1.96 \\
\hline & & $10 \mathrm{mg}$ & 78 & 29.5 & 164.40 & 2.64 \\
\hline & & $20 \mathrm{mg}$ & 119 & 49.50 & 140.40 & 2.40 \\
\hline 13. & T. Diltiazam & $30 \mathrm{mg}$ & 26.26 & 17.25 & 52.23 & 1.52 \\
\hline & & $60 \mathrm{mg}$ & 37.50 & 29.31 & 27.94 & 1.27 \\
\hline$\beta$-bloc & & & & & & \\
\hline 14. & T. Atenolol & $25 \mathrm{mg}$ & 24.10 & 7.9 & 202.76 & 3.02 \\
\hline & & $50 \mathrm{mg}$ & 23.07 & 5.81 & 297.07 & 3.97 \\
\hline & & $100 \mathrm{mg}$ & 35.52 & 6.77 & 424.66 & 5.24 \\
\hline 15. & T. Carvedilol & $3.125 \mathrm{mg}$ & 30.24 & 9.00 & 236 & 3.36 \\
\hline & & $6.25 \mathrm{mg}$ & 44.50 & 17.93 & 148.18 & 2.48 \\
\hline & & $12.5 \mathrm{mg}$ & 77.33 & 30 & 157.76 & 2.57 \\
\hline & & $25 \mathrm{mg}$ & 122 & 52 & 134.61 & 2.32 \\
\hline 16. & T. Labetolol & $100 \mathrm{mg}$ & 137 & 122 & 12.29 & 1.12 \\
\hline 17. & T. Metoprolol & $25 \mathrm{mg}$ & 46.64 & 18.01 & 158.96 & 2.58 \\
\hline & & $50 \mathrm{mg}$ & 67.61 & 32.80 & 106.31 & 2.06 \\
\hline 18. & T. Nebivolol & $2.5 \mathrm{mg}$ & 103.66 & 32 & 223.93 & 3.23 \\
\hline & & $5 \mathrm{mg}$ & 113.10 & 50.20 & 125.29 & 2.25 \\
\hline 19. & T. Propranolol & $10 \mathrm{mg}$ & 17 & 8.25 & 106.06 & 2.06 \\
\hline & & $20 \mathrm{mg}$ & 25.84 & 18.50 & 39.67 & 1.39 \\
\hline & & $40 \mathrm{mg}$ & 74.25 & 26.01 & 185.46 & 2.85 \\
\hline
\end{tabular}




\begin{tabular}{|c|c|c|c|c|c|c|}
\hline \multicolumn{7}{|c|}{ Centrally acting sympatholytic agents } \\
\hline 20. & T. Methyldopa & $250 \mathrm{mg}$ & 24.15 & 21.77 & 10.93 & 1.10 \\
\hline \multicolumn{7}{|c|}{ a-blocker } \\
\hline \multirow[t]{2}{*}{21.} & T. Prozion & $2.5 \mathrm{mg}$ & 114.43 & 80.16 & 42.75 & 1.42 \\
\hline & & $5 \mathrm{mg}$ & 125.33 & 107.66 & 16.41 & 1.16 \\
\hline \multicolumn{7}{|c|}{ Vasodilator } \\
\hline \multirow[t]{2}{*}{22.} & T. Cinnarizine & $25 \mathrm{mg}$ & 36.50 & 13.75 & 165.45 & 2.65 \\
\hline & & $75 \mathrm{mg}$ & 43.20 & 32.2 & 34.16 & 1.34 \\
\hline \multirow[t]{3}{*}{23.} & T. Isoxsuprine & $10 \mathrm{mg}$ & 21.66 & 15 & 44.4 & 1.44 \\
\hline & & $20 \mathrm{mg}$ & 34.60 & 27 & 28.14 & 1.28 \\
\hline & & $40 \mathrm{mg}$ & 55 & 44.00 & 25 & 1.25 \\
\hline
\end{tabular}

(mg) - milligram, T - Tablet

Fig: 1 Cost variation of maximum price and minimum price of commonly used antihypertensive drugs used as single therapy

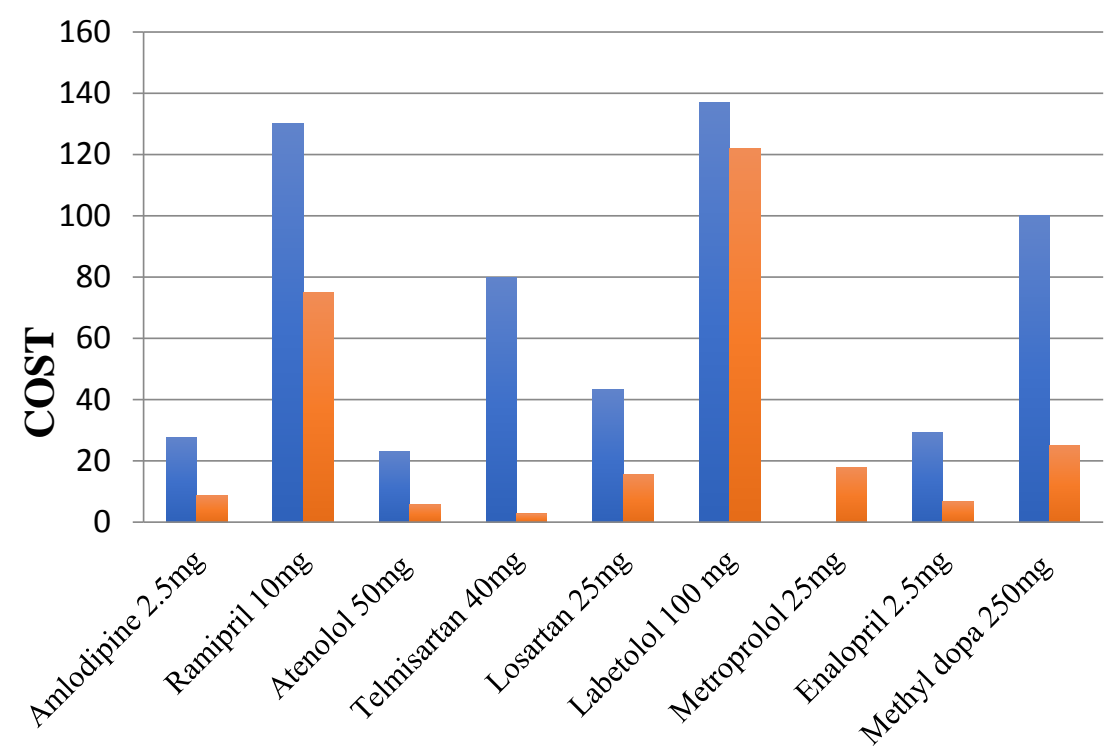

- Maximum cost (INR)

$\square$ Minimum cost (INR)

DRUGS

Fig: 2 Percentage cost variation of commonly used antihypertensive drugs used as single drug therapy

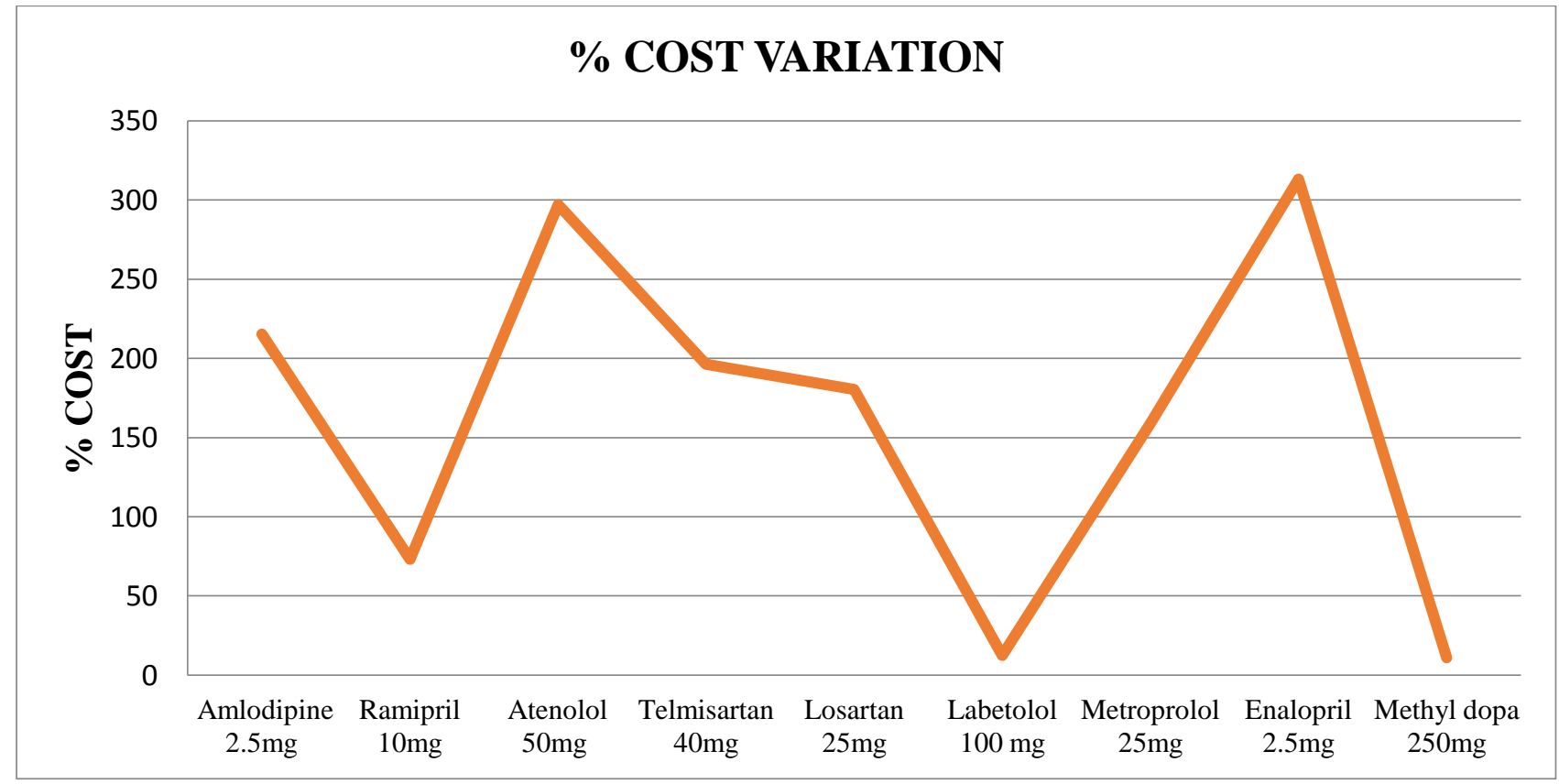

Fig: 3 Cost ratios of commonly used antihypertensive drugs used as a single drug therapy 


\section{COST RATIO}

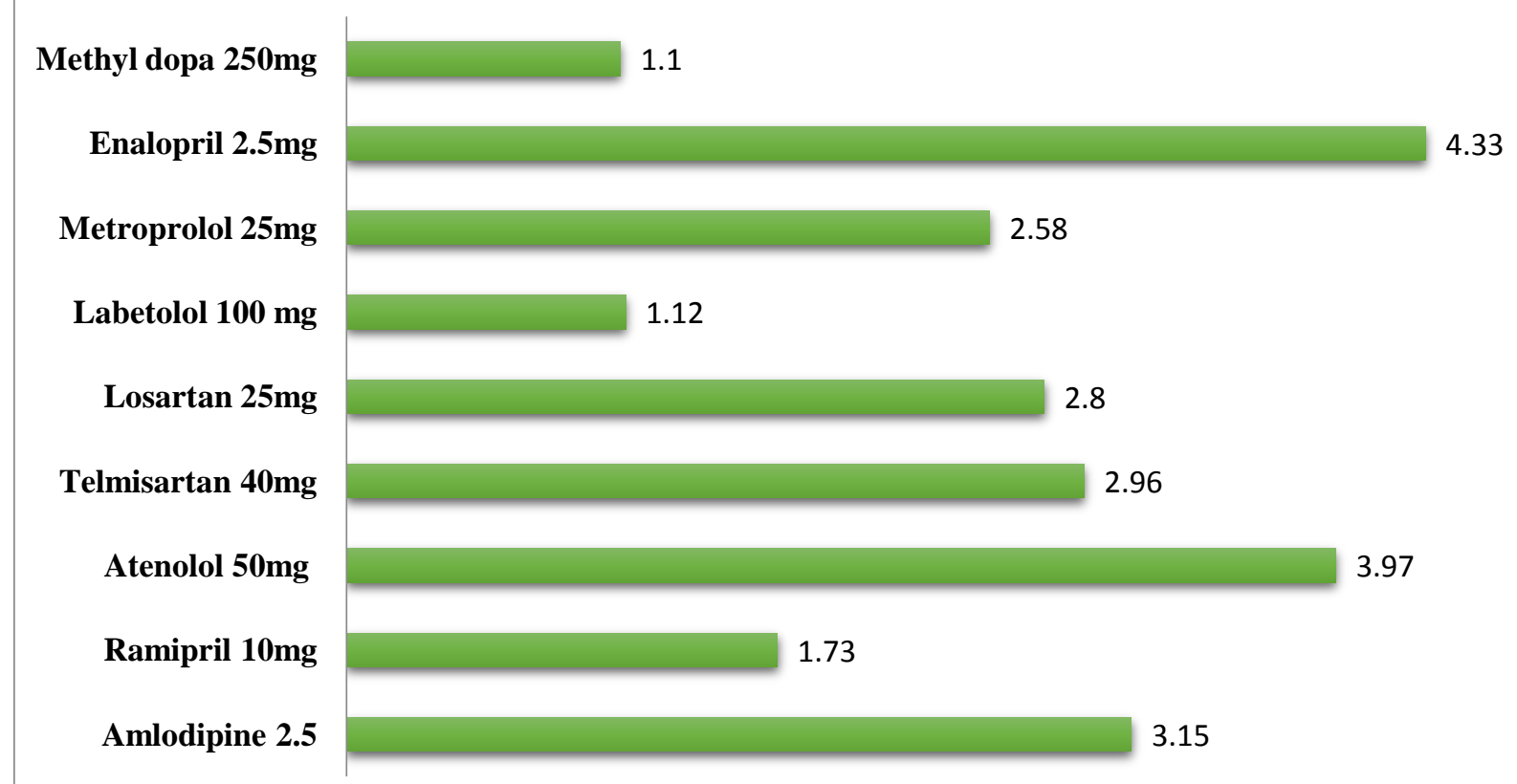

\section{Discussion}

The present study reveals that the high fluctuations are seen in oral antihypertensive; variation of cost being manufactured by several companies (Fig 1). The percentage of cost variation was seems to be above $100 \%$ for majority of drugs which is used commonly by the patients (Fig 2). Cost ratio also observed to have more high deviations in chart (Fig 3).

A related study of Kamath $\mathrm{L}$ also showed that higher deviations of cost variation in different brands of antihypertensive drugs ${ }^{(10)}$. There are more similar studies have been performed on oral hypoglycemics, anxiety, ocular preparations, antiglaucoma drugs, oral hypolipidemics, tuberculosis, anticancer are also found the related results ${ }^{(11-16)}$.

These variations are due to competitions between different brands of drugs manufactured by companies. Drug Price Control Order (DPCO) is order established by government of India where all the price of the drugs must be according to DPCO as per they fixes the rate of the drugs. These drugs cannot dispense at the price more than the pointed rate by the government of India (17). Here, physician and pharmacist also play a vital role by initiating and dispensing specific brands of high cost for their economic gain. This wide variation of prices of different formulations of same drug may leads to a severe economic impact. In India doctors have less awareness in cost difference of different brands of same drug. Hence prescribing generic names are more appreciable, so patients can choose the affordable brands $^{(18)}$.

\section{Conclusion}

Our current study reveals that there was a huge variation of cost in drugs which was manufactured from various pharmaceutical companies. To be said poor knowledge and condition of health care system also the important reason for the patient's burden. Hence physicians can prescribe the drugs in generic forms and patients can save their money and their therapeutic compliance will be increased. An awareness must be created about the maximum variation of cost to the physicians, pharmacist and health care management to our economic benefits for patients and increase their benefits of therapy.

Authorship statement: All the authors in the study have contributed their equal parts and comply with the journals authorship policy. 
Conflict of Interest: The authors do not state any conflict of interest.

Ethical committee approval: Not required Acknowledgement: Nil

\section{Reference}

1. Rajan AK, Sabishruthi S, Manivendra G, Benita ES, Mukesh M. Appraisal of Health Related Quality of Life Among Hypertensive Patients in A Tertiary Care Hospital in South India. International Journal of Current Innovation Research. 2018; 4(11): 1401-1404.

2. Nair MK, Neha MS. Cost variation analysis of antihypertensive drugs acting through renin angiotensin aldosterone axis modulation. Int $\mathbf{J}$ Basic ClinPharmacol. 2017;6:1085-9.

3. Kumar R, Manu C, Singh DJ, Lakhani P, Tutu S, Dixit R. The extent of price variation amongst branded antihypertensive drugs and its association with number of pharmaceutical companies. Int J Res Med Sci. 2015;3:2800-6.

4. Moran AE et al. Cost-Effectiveness of Hypertension Therapy According to 2014 Guidelines. N Engl J Med. 2015; 372(5): 447-455.

5. Ce'sar Gonzalo Calvo-Vargas, Jose' Z. Parra Carrillo, Fernando Grover Pa'ez, and Salvador Fonseca Reyes. Changes in the Costs of Antihypertensive Medications in a Developing Country A Study in Mexico Comparing 1990 and 1996. AJH. 1998;11:487-493.

6. Rachana PR, Anuradha HV, MC Shivamurthy. Anti Hypertensive Prescribing Patterns and Cost Analysis for Primary Hypertension: A Retrospective Study. Journal of Clinical and Diagnostic Research. 2014; 8(9): 19-22.

7. Kullgren JT, Segel JE, Peterson TA, Fendrick AM, Singh S. Availability and Variation of Publicly Reported
Prescription Drug Prices.Am J Manag Care. 2017;23(7):444-448.

8. Shubham Atal, SarjanaAtal,

DeshmankarB, Nawaz SA. Cost Analysis Of Commonly Used Drugs Under Price Control In India: Assessing The Effect Of Drug Price Control Order On Brand Price Variation. Int J Pharm Pharm Sci. 2016; 8(4): 315-321.

9. Mamatha K.R, Vishnu K. Cost variation analysis of various brands of oral hypolipidemic drugs available in Indian pharmaceutical market. Int. J. of Res. in Pharmacology \& Pharmacotherapeutics. 2017; 6(3): 381-388.

10. Kamath L and Satish GR. Cost Variation Analysis of Antihypertensive Drugs Available in Indian Market: An Economic Perspective. Int J Pharm Sci Res. 2016; 7(5): 2050-56.

11. Chawan VS, Badwane SV, Gawand KV, Chhaya MU. Analysis of price variation amongst different formulations of anxiolytic drugs available in Indian market. Int J Res Med Sci. 2016;4:2398401.

12. Chandrappa S, Rajarathna K. Cost variation analysis of various brands of topical eye preparations currently available in Indian pharmaceutical market. Int $\mathbf{J}$ Basic ClinPharmacol. 2018;7:2364-7.

13. Jadhao T, Advani M, Jamdade S. Cost variation analysis of antiglaucoma drugs available in Indian market. Paripex Indian Journal of Research. 2017; 6(2): 4243.

14. Chaudhari A, Zaveri JR. Pharmacoecoeconomic study: A cost variation analysis of AKT drugs available in Indian market. Indian J Pharm Pharmacol. 2019; 6(1): 610.

15. Lakdawala A. Cost variation analysis of oral hypolipidemic drugs available in Indian market. International Journal of Research and Review. 2018; 5(9):1-4. 
16. Bhanu Prakash kolaSani1, Divya Shanthi Chellatham Bimalathi2, raghunatharao Ponnaluri3. Variation of Cost among Anticancer Drugs Available in Indian Market. Journal of Clinical and Diagnostic Research. 2016; 10(11): 17-20.

17. Bhandari PR. Analysis of Cost Variation of Hypolipidemics. J Pharm Biomed Sci. 2019; 09(04): 35-42.

18. Shrestha B. Cost analysis of oral antihypertensive agents available in Nepal. Journal of Institute of Medicine. 2015; 37(2): 27-31. 